\title{
Afyonkarahisar ilinde farklı sütlerden üretilip, değişik ambalaj malzemeleri içeresinde satışa sunulan Tulum peynirlerinin kimyasal ve mikrobiyolojik özellikleri
}

\section{Chemical and microbiological properties of Tulum cheeses produced from different milks and marketed in different packaging materials in Afyonkarahisar}

\author{
Oktay TOMAR ${ }^{\circledR}$, Gökhan AKARCA( \\ Afyon Kocatepe Üniversitesi, Mühendislik Fakültesi, Gıda Mühendisliği Bölümü, Afyonkarahisar, Türkiye \\ Sorumlu yazar (Corresponding author): O. Tomar, e-posta (e-mail): oktaytomar@hotmail.com \\ Yazar(lar) e-posta (Author e-mail): gakarca@aku.edu.tr
}

\section{MAKALE BİLGİSİ}

Alınış tarihi 02 Mayıs 2019

Düzeltilme tarihi 19 Mayıs 2019

Kabul tarihi 20 Mayıs 2019

\section{Anahtar Kelimeler:}

Afyonkarahisar

Tulum Peyniri

Kimyasal

Mikrobiyolojik

Kalite

\begin{abstract}
ÖZ
Bu çalışmada Afyonkarahisar ilinde farklı sütlerden (inek, koyun ve keçi) üretilip ve üç farklı ambalaj malzemesi Tulum, bidon ve çuval) içerisinde satışa sunulan tulum peynirlerinin kimyasal ve mikrobiyolojik kaliteleri araştırılmıştır. İncelenen toplam 135 numunenin en yüksek pH, \% titrasyon asitliği, su aktivitesi $\left(\mathrm{a}_{\mathrm{w}}\right)$, kurumadde $(\%)$ ve yağ $(\%)$ değerleri sirasıyla, 5.23, $0.71,0.882,54.38$ ve 46.5 en düşük; $3.97,0.39,0.724,52.18$ ve 20.0 olarak belirlenmiştir. Bidon ambalajlar içerisinde satışa sunulan örneklerin $\mathrm{pH}$ laktik asit cinsinden \% titrasyon asitliği, $a_{w}$, kurumadde ve yağ değerlerinin diğer ambalaj malzemeleri ile satılan örneklere kıyasla daha düşük olduğu tespit edilmiştir. Örneklerin toplam aerobik mezofilik bakteri, maya/küf, toplam koliform grubu bakteri, laktik asit bakterisi, Lactococcus/Streptococcus spp. ve Staphylococcus aureus türü bakteri sayıları sirasıyla en fazla7.21, 6.92, 4.67, 4.92, 4.58 ve $4.03 \mathrm{log} \mathrm{kob} \mathrm{g}^{-1}$, en düşük $3.42,3.56,<2,3.38,3.23$ ve <2 $\log \mathrm{kob} \mathrm{g}^{-1}$ olarak tespit edilmiştir. Ayrıca 135 peynir örneğinin 18 adedinde Escherichia coli ve 21 adedinde Salmonella spp. varlığı saptanmıştır. Tulum peynirlerinin mikrobiyolojik kalitelerinin kimyasal kalitelerinden, çok daha düşük olduğu sonucuna varılmıştır. Mikrobiyolojik analizler sonucunda en fazla mikroorganizma varlığının üretildikten sonra çuval ambalajlar içerisinde satışa sunulan örneklerde olduğu belirlenmiştir.
\end{abstract}

\section{ARTICLE INFO}

Received 02 May 2019

Received in revised form 19 May 2019

Accepted 20 May 2019

\section{Keywords:}

Afyonkarahisar

Tulum Cheese

Chemical

Microbiological

Quality

\begin{abstract}
In this study, chemical and microbiological qualities of Tulum cheeses produced from different milk (cow, sheep and goat milks) and marketed in three different packaging materials in Afyonkarahisar were investigated. A total of 135 samples were examined. The highest $\mathrm{pH}$, $\%$ titratable acidity, water activity (aw), dry matter $(\%)$ and fat $(\%)$ values were found to be $5.23,0.71,0.882,54.38$ and 46.5 while the lowest values were found to be $3.97,0.39,0.724$, 52.18 and 20.0, respectively. It was determined that, the $\mathrm{pH}$, lactic acid \%, titratable acidity, aw, dry matter and fat values of the samples marketed in plastic cans were lower than those of the samples marketed with other packaging materials. The highest total aerobic mesophilic bacteria, yeast/mold, total coliform group bacteria, lactic acid bacteria, Lactococcus/Streptococcus spp. and Staphylococcus aureus counts of the samples were found to be $7.21,6.92,4.67,4.92,4.58$ and $4.03 \mathrm{log} \mathrm{kob} \mathrm{g}^{-1}$, while the lowest values were 3.42, 3.56, $<2,3.38,3.23$ and $<2 \log \mathrm{kob} \mathrm{g}^{-1}$, respectively. In addition, of the 135 cheese samples, Escherichia coli was detected in 18 samples while Salmonella spp. was detected in 21 samples. The microbiological qualities of Tulum cheese samples were found to be much lower than their chemical qualities. As a result of microbiological analyzes, the highest microorganism counts were determined in the samples marketed in sack packaging.
\end{abstract}

\section{Giriş}

Tulum peyniri bugün Türkiye'de üretilen 100'den fazla çeşit peynir içerisinde en fazla tüketilen ilk üç peynir türü arasında yer almaktadır (Çakır ve Çakmakçı 2018). Olgunlaştırıldıktan sonra tüketilen peynirler sınıfında olan 
Tulum peyniri, kendine has tekstürel ve duyusal özelliklere sahip, beyaz veya krem renginde, yüksek yağ içerikli, kolay ufalanabilen, yarı sert tekstürlü, tereyağımsı ve keskin kokulu bir peynir türüdür (Karaca ve ark. 2007). Tulum peyniri hemen her bölgede üretilmesine karşın; hammadde, üretim şekli, yapısı, olgunlaştırma koşulları ve içerisine konulan ambalaj malzemeleri açısından yöresel farklılıklar göstermektedir (Kirdar ve ark. 2015). Bu kadar çok çeşit tulum peyniri arasında en popüler olanlar Erzincan, Afyon, İzmir ve Konya Tulum peynirleridir (Çetinkaya 2008). Türkiye'de tulum peyniri kuru ve salamura tipi olmak üzere iki farklı şekilde üretilmektedir. Kuru tulum peynirleri çoğunlukla Orta, Doğu ve Güneydoğu Anadolu Bölgelerinde, salamura tulum peynirleri ise çoğunlukla Ege Bölgesi'nin batısında üretilmektedir (Tekinşen ve Tekinşen 2005). Genellikle koyun derisinden üretilen tulumlar içerisine doldurulan peynirlerin günümüzde üretimlerinde plastik bidon, testi, bağırsak, karın ve suni kılıflar gibi pek çok farklı ambalaj kullanılabilmektedir (Tomar ve ark. 2018).

Bununla birlikte üretim, saklama ve satış koşulları ile kullanılan ambalaj malzemelerinden kaynaklanan sorunlar tulum peynirlerinin mikrobiyolojik kalitelerini olumsuz etkilemektedir. $\mathrm{Bu}$ durum hem ürünlerin kalitesinin bozulmasına yol açmakta hem de tüketicilerin sağlığı üzerinde ciddi riskler oluşturmaktadır.

$\mathrm{Bu}$ çalışmada; Afyonkarahisar ilinde farklı sütlerden üretilerek, değişik ambalaj malzemeleri içerisinde satışa sunulan tulum peynirlerinin kimyasal ve mikrobiyolojik kalitelerinin incelenmesi amaçlanmıştır.

\section{Materyal ve Yöntem}

Araştırmada; farklı sütlerden üretilmiş (inek, koyun ve keçi sütleri) ve farklı ambalaj malzemeleri (tulum, bidon ve çuval) içerisinde satışa sunulan, toplam 135 adet tulum peyniri numunesi kullanılmıştır. Peynirler Afyonkarahisar ilinde faaliyet gösteren satış noktalarından, farklı zaman dilimlerinde alınmıştır. Örnekler satışa sunuldukları ambalajlar içerisinde ve en az 250 g olacak şekilde alınarak soğuk zincir altında Afyon Kocatepe Üniversitesi Mühendislik Fakültesi Gıda Mühendisliği Bölümü laboratuvarlarına getirilmiş ve analizleri tamamlanıncaya kadar buzdolabında $\left(+4^{\circ} \mathrm{C}^{\prime} \mathrm{de}\right)$ muhafaza edilmiştir.

Tulum peyniri örneklerinin, \% titrasyon asitliği AOAC 942.15, yağ AOAC 933.05 ve kurumadde analizleri AOAC 930.15'e göre yapılmıștır (AOAC 2016a, 2016b, 2016c). Numunelerinin pH değerleri, Ohaus (ST 5000, ABD) ile AOAC 981.1'e göre, aw değerleri ise; Novasina LabTouch-aw (Novasina AG, Lachen, İsviçre) ile AOAC 978.18'e göre belirlenmiştir (AOAC 2016d, 2016e).

Tulum peyniri numunelerinde, toplam aerobik mezofilik bakteri (TAMB), maya/küf, toplam koliform grup bakteri (TKGB), laktik asit bakterisi (LAB), Lactococcus/Streptococcus türü bakteri, Staphylococcus aureus türü bakteri, Escherichia coli ve Salmonella spp. cinsi bakteri varlıkları yayma plak yöntemi kullanılarak tespit edilmiştir (Halkman ve Sağdaş 2011).

Peynir örneklerinden steril koşullar altında $10 \mathrm{~g}$ alınarak, steril stomacher poşetlerine (Spa-174538, Lp Italiana, Milan, İtalya) aktarılmış ve $10^{-6}$ ya kadar seri dilüsyonlar hazırlanmıştır (Anonim 2001; Sekin ve Karagözlü 2004).

Toplam aerobik mezofilik bakteri sayısı analizi, Plate Count Agar (PCA) (Merch, Almanya, 1.05463) besiyeri kullanılarak yapılmıştır. Ekimi yapılan petri kutuları aerobik koşullarda TAMB sayım için $30^{\circ} \mathrm{C}$ 'de $48-72$ saat etüvde (MM Incucell 55, Almanya) inkübasyona bırakılmıştır (ISO 2013a; ISO 2013b). Maya/küf sayısı analizi için Patates Dekstroz Agar (PDA) (Merch, Almanya, 1.10130) besiyeri kullanılmış ve ekimi yapılan petri kutuları aerobik koşullarda $22^{\circ} \mathrm{C}$ 'de 5-7 gün etüvde (MM Incucell 55, Almanya) inkübasyona tabi tutulmuştur (ISO 2008). Toplam koliform grubu bakteri sayımı için Violet Red Bile Agar (VRB) (Merch, Almanya, 1.01406) besiyeri kullanılmış, petri kutuları aerobik koşullarda $30^{\circ} \mathrm{C}$ 'de 24-48 saat etüvde (MM Incucell 55, Almanya) inkübasyona bırakılmıştır (ISO 1991). Laktik asit bakterisi sayısı için ise, Man Rogasa and Sharpe Agar (MRS) (Merch, Almanya, 1.10660) besiyeri kullanılmıș, petri kutuları jar içeresinde (Merck 1.16387) anaerobik koşullarda $30^{\circ} \mathrm{C}$ 'de $24-48$ saat etüvde (Daihan, IG50, Malezya) inkübe edilmiştir (Kneifel and Berger 1994). Lactococcus/Streptococcus spp. türü bakteri analizleri için M-17 Agar besiyeri (Merch, Almanya, 1.15108) kullanılmış, petri kutuları aerobik koşullarda $30^{\circ} \mathrm{C}$ 'de $24-48$ saat etüvde (Daihan, IG50, Malezya) inkübasyona bırakılmıştır (Halkman 2005).

Staphylococcus aureus türü bakteri sayısı ve Escherichia coli türü bakteri analizleri sirasıyla, Baird Parker Agar Merch, Almanya, 1.05406) ve Chromocult TBX Agar Merch, Almanya, 1.16122) besiyerleri kullanılarak yapılmıștır. Ekimi yapılan petri kutuları aerobik koşullarda sırasılyla $30-35$ ve $37^{\circ} \mathrm{C}$ 'lerde 24-48 saat etüvde (MM Incucell 55, Almanya) inkübasyona tabi tutulmuştur. Süre sonunda Staphylococcus aureus türü bakteriler için şüpheli kolonilerden (etrafı beyaz zonlu siyah) örnekler alınarak yeniden Baird Parker Agar'a ekim yapılmış olup, aynı süre ve koşullarda bir kez daha inkübasyona bırakılmıştır. İnkübasyon sonucunda gelişen kolonilerden alınarak Bactident Coagulase (Merck, Almanya, 1.13306) ile koagulaz testi uygulanmış ve pozitif sonuç verenler Staphylococcus aureus olarak değerlendirilmiştir. Escherichia coli türü bakteriler için ise inkübasyon sonrasında gelișen koloniler, UV (366 nm) 1şık altında kontrol edilmiştir (ISO 1999; ISO 2001; ISO 2015).

Salmonella spp. cinsi bakteri analizi yayma plak metodu ile Nutrient Broth (NB) (Merck, Almanya 1.05443), Rappaport Vassiliadis Salmonella Enrichment Broth (RVS) (Merck, Almanya, 1.07700), Brilliant Green Phenol Red Lactose Sucrose Agar (BPLS) (Merck, Almanya 1.10747) ve Xylose Lysine Deoxycholate Agar (XLD) (Merck, Almanya, 1.105287) kullanılarak yapılmıştır. Ekimi yapılan petri kutuları aerobik koşullarda $37^{\circ} \mathrm{C}$ 'de $24-48$ saat inkubasyona bırakılmıştır (Greenwood et al. 1984; Flowers et al. 1992; ISO 2017).

\section{Bulgular ve Tartışma}

Değişik ambalaj malzemeleri içerisinde satışa sunulan tulum peyniri örneklerinin $\mathrm{pH}$ değerleri inek sütünden üretilenler, koyun sütünden üretilenler ve keçi sütünden üretilenleri olmak üzere sırasıyla Çizelge 1, Çizelge 2 ve Çizelge 3 'te gösterilmiştir.

Peynirler arasında ortalama değerler açısından en düşük $\mathrm{pH}$ ve en yüksek \% titrasyon asitliği değerleri sirasıyla $4.24 \pm 0.26$ ve $\% 0.59 \pm 0.03$ olarak koyun sütünden üretilip, bidon ambalajlar içerisinde satışa sunulan örneklerde tespit edilmiş, en yüksek $\mathrm{pH}$ ve en düşük \% titrasyon asitliği değerlerinin ise sırasıyla $5.42 \pm 2.40$ ve $\% 0.26 \pm 0.07$ olmak üzere keçi sütünden üretilip çuvallar içerisinde satışa sunulan tulum peynir örneklerinde olduğu belirlenmiştir. Ayrıca, üç farklı süt kullanılarak üretilen 
Çizelge 1. İnek sütünden üretilerek farklı ambalajlar içerisinde satışa sunulan Tulum peyniri örneklerinin kimyasal analiz sonuçları.

Table 1. Chemical analysis results of Tulum cheese samples produced from cow's milk and sold in different packages.

\begin{tabular}{|c|c|c|c|c|}
\hline \multirow[b]{2}{*}{ Ambalaj } & \multirow[b]{2}{*}{ Analiz } & \multicolumn{3}{|c|}{ Numune (n: $15 \times$ 3) } \\
\hline & & Minimum & Maksimum & Ortalama \\
\hline \multirow{5}{*}{ Tulum } & $\mathrm{pH}$ & 4.55 & 5.32 & $5.03 \pm 0.16$ \\
\hline & Titrasyon asitliği (\%) & 0.43 & 0.38 & $0.40 \pm 0.02$ \\
\hline & Kurumadde $(\%)$ & 54.38 & 60.23 & $59.88 \pm 1.95$ \\
\hline & Su aktivitesi & 0.724 & 0.810 & $0.763 \pm 0.33$ \\
\hline & Yağ (\%) & 24.0 & 34.0 & $32.2 \pm 2.10$ \\
\hline \multirow{5}{*}{ Bidon } & $\mathrm{pH}$ & 4.22 & 5.03 & $4.48 \pm 0.20$ \\
\hline & Titrasyon asitliği (\%) & 0.47 & 0.40 & $0.51 \pm 0.11$ \\
\hline & Kurumadde & 49.71 & 56.43 & $50.38 \pm 2.72$ \\
\hline & Su aktivitesi & 0.836 & 0.922 & $0.912 \pm 0.16$ \\
\hline & Yağ (\%) & 20.0 & 32.0 & $29.4 \pm 2.10$ \\
\hline \multirow{5}{*}{ Çuval } & $\mathrm{pH}$ & 4.26 & 5.17 & $4.89 \pm 0.18$ \\
\hline & Titrasyon asitliği (\%) & 0.49 & 0.38 & $0.46 \pm 0.04$ \\
\hline & Kurumadde & 52.18 & 59.34 & $55.11 \pm 1.47$ \\
\hline & Su aktivitesi & 0.778 & 0.854 & $0.818 \pm 0.34$ \\
\hline & Yağ (\%) & 22.0 & 30.0 & $28.2 \pm 2.20$ \\
\hline
\end{tabular}

Çizelge 2. Koyun sütünden üretilerek farklı ambalajlar içerisinde satışa sunulan Tulum peyniri örneklerinin kimyasal analiz sonuçları.

Table 2. Chemical analysis results of Tulum cheese samples produced from sheep's milk and sold in different packages.

\begin{tabular}{|c|c|c|c|c|}
\hline \multirow[b]{2}{*}{ Ambalaj } & \multirow[b]{2}{*}{ Analiz } & \multicolumn{3}{|c|}{ Numune (n: 15 x 3) } \\
\hline & & Minimum & Maksimum & Ortalama \\
\hline \multirow{5}{*}{ Tulum } & $\mathrm{pH}$ & 4.47 & 4.86 & $4.74 \pm 0.09$ \\
\hline & Titrasyon asitliği (\%) & 0.47 & 0.42 & $0.44 \pm 0.03$ \\
\hline & Kurumadde $(\%)$ & 53.64 & 63.27 & $57.36 \pm 6.15$ \\
\hline & Su aktivitesi & 0.765 & 0.858 & $0.816 \pm 0.22$ \\
\hline & Yağ (\%) & 27.4 & 44.6 & $38.4 \pm 2.16$ \\
\hline \multirow{5}{*}{ Bidon } & $\mathrm{pH}$ & 3.97 & 4.32 & $4.24 \pm 0.26$ \\
\hline & Titrasyon asitliği (\%) & 0.71 & 0.37 & $0.59 \pm 0.03$ \\
\hline & Kurumadde & 50.27 & 57.31 & $52.84 \pm 4.06$ \\
\hline & Su aktivitesi & 0.823 & 0.941 & $0.906 \pm 0.13$ \\
\hline & Yağ (\%) & 23.2 & 40.5 & $34.2 \pm 1.20$ \\
\hline \multirow{5}{*}{ Çuval } & $\mathrm{pH}$ & 4.68 & 4.77 & $4.75 \pm 0.12$ \\
\hline & Titrasyon asitliği (\%) & 0.46 & 0.40 & $0.42 \pm 0.08$ \\
\hline & Kurumadde & 52.18 & 60.68 & $54.48 \pm 4.86$ \\
\hline & Su aktivitesi & 0.882 & 0.836 & $0.844 \pm 0.11$ \\
\hline & Yağ $(\%)$ & 28.8 & 46.5 & $32.50 \pm 3.20$ \\
\hline
\end{tabular}

Çizelge 3. Keçi sütünden üretilerek farklı ambalajlar içerisinde satışa sunulan Tulum peyniri örneklerinin kimyasal analiz sonuçları.

Table 3. Chemical analysis results of Tulum cheese samples produced from goat's milk and sold in different packages.

\begin{tabular}{|c|c|c|c|c|}
\hline \multirow[b]{2}{*}{ Ambalaj } & \multirow[b]{2}{*}{ Analiz } & \multicolumn{3}{|c|}{ Numune (n: 15 x 3) } \\
\hline & & Minimum & Maksimum & Ortalama \\
\hline \multirow{5}{*}{ Tulum } & $\mathrm{pH}$ & 4.45 & 5.12 & $5.04 \pm 0.21$ \\
\hline & Titrasyon asitliği (\%) & 0.28 & 0.42 & $0.36 \pm 0.04$ \\
\hline & Kurumadde (\%) & 51.14 & 57.32 & $54.48 \pm 4.24$ \\
\hline & Su aktivitesi & 0.838 & 0.876 & $0.854 \pm 0.42$ \\
\hline & Yağ (\%) & 22.5 & 38.1 & $32.54 \pm 3.50$ \\
\hline \multirow{5}{*}{ Bidon } & $\mathrm{pH}$ & 4.02 & 5.74 & $4.86 \pm 2.40$ \\
\hline & Titrasyon asitliği (\%) & 0.53 & 0.36 & $0.42 \pm 0.06$ \\
\hline & Kurumadde & 46.35 & 59.63 & $49.18 \pm 5.25$ \\
\hline & Su aktivitesi & 0.858 & 0.905 & $0.897 \pm 0.23$ \\
\hline & Yağ (\%) & 20.2 & 30.2 & $26.55 \pm 2.25$ \\
\hline \multirow{5}{*}{ Çuval } & $\mathrm{pH}$ & 5.23 & 6.03 & $5.42 \pm 2.40$ \\
\hline & Titrasyon asitliği (\%) & 0.39 & 0.21 & $0.26 \pm 0.07$ \\
\hline & Kurumadde & 50.66 & 58.24 & $52.65 \pm 3.27$ \\
\hline & Su aktivitesi & 0.841 & 0.883 & $0.861 \pm 0.34$ \\
\hline & Yağ (\%) & 24.4 & 34.24 & $30.68 \pm 2.02$ \\
\hline
\end{tabular}


tulum peynir örneklerinin tamamında en düşük $\mathrm{pH}$ ve en yüksek $\%$ titrasyon asitliği değerlerinin bidon ambalajlar içerisinde satışa sunulan örneklerde olduğu saptanmıştır. Bidon ambalajlarda satışa sunulan peynirlerin su aktivite değerlerinin de diğer ambalajlar içerisinde satışa sunulan örneklerden daha yüksek olmasının, bidon ambalajın içerindeki tulum peynirlerinde bulunan starter ve non starter bakterilerin gelişimi için daha uygun ve uzun süreli bir ortam oluşturmasından ve bunun neticesinde de metabolik aktiviteye bağlı daha fazla laktik asit üretimi gerçekleşmiş olmasından kaynaklandığı değerlendirilmiştir.

Çalım (2007), araştırmasında Konya Tulum peynirlerinin $\mathrm{pH}$ ve \% titrasyon asitliği değerlerinin sırasıyla \%0.72-1.07 ve 5.02-5.38 aralığında olduğunu belirlemiş, Kara ve Akkaya (2015) ise Afyon Tulum peynirlerinin $\mathrm{pH}$ ve \% titrasyon asitliği değerlerinin sırasıyla 5.27 ve $\% 0.51$ olduğunu tespit etmiş̧lerdir. Çalışmalarda elde edilen bulgular ile araştırmamız sonuçları arasında çok fazla olmamakla birlikte, mevsim, hammadde, proses, ambalaj, depolama ve olgunlaştırma aşamalarındaki değişkenlerin farklılığa neden olduğu düşünülmektedir.

Ortalama değerler açısından en düşük su aktivitesi ve en yüksek kurumadde değerleri sirasiyla $0.763 \pm 0.33$ ve $\% 59.88 \pm 1.95$ olmak üzere inek sütünden üretilip, tulum ambalaj içerisinde satışa sunulan örneklerde, en yüksek su aktivitesi ve en düşük kurumadde değerleri ise sirasıyla $0.912 \pm 0.16$ ve $\% 50.38 \pm 2.72$ olmak üzere koyun sütünden üretilen ve bidon ambalajlar içerisinde satışa sunulan peynir örneklerinde tespit edilmiştir. Benzer şekilde peynir örnekleri arasında en yüksek su aktivitesi ve en düşük kurumadde değerlerine sahip olan tüm örneklerin bidon ambalajlar içerisinde satışa sunulan peynirler olduğu belirlenmiştir. Elde edilen bu sonuçların; bidon ambalajların su geçirgenliğinin olmaması, olgunlaştırma ve depolama aşamalarında bu peynirlerin diğer örneklere kıyasla daha az nem kaybetmesinden kaynaklandığı düşünülmektedir.

Kara ve Akkaya (2011), tarafindan yapılan çalışmada Afyon Tulum peyniri örneklerinin su aktivitesi değerlerinin 0.76 ile 0.89 aralığında değiştiği, peynirlerde ortalama su aktivitesi değerinin 0.85 olduğu tespit edilmiştir.

Tulum peyniri örneklerinin yağ içeriklerinin, inek sütünden üretilen peynirlerde $\% 20$ ile $\% 34$ arasında, koyun sütü ile üretilen peynirlerde $\% 23.2$ ile 46.5 arasında ve keçi sütünden üretilen peynirlerde ise \%20.2 ile 38.1 arasında değişim gösterdiği belirlenmiştir. Bostan ve ark. (1992), deri ve plastik bidonlar içinde satışa sunulan tulum peynirlerinin yağ oranlarını ortalama \%24.5; Ceylan ve ark. (2007) ise Erzincan (Şavak) Tulum peynirlerin yağ oranlarını ortalama \%30.0 olarak belirlemişlerdir.

Tulum peynirlerinin en yüksek TAMB sayıs1 ise 7.41 $\log \mathrm{kob} \mathrm{g}^{-1}$ (Çizelge 4) ile inek sütünden üretilip çuval ambalaj içerisinde satışa sunulan peynirlerde, en düşük TAMB sayısı $3.42 \log \mathrm{kob} \mathrm{g}^{-1}$ (Çizelge 5) ile koyun sütünden üretilip tulum ambalaj içerisinde satışa sunulan peynir örneklerinde olduğu tespit edilmiştir.

Örneklerde TAMB sayısının yüksek olması, peynirlerin çiğ sütten üretilmiş olabileceğinin ve/veya üretim ve ambalajlama aşamalarında meydana gelebilen kontaminasyonların göstergesi olarak değerlendirilmektedir (Kurt ve ark. 1991; Demir ve ark. 2018).

Demir ve ark. (2018), Elazığda ilinde satışa sunulan Şavak Tulum peynirlerinin TAMB sayısının en az $3.12 \log \mathrm{kob} \mathrm{g}^{-1}$, en fazla $8.03 \log \mathrm{kob} \mathrm{g}^{-1}$ ve ortalama olarak $6.85 \pm 2.11 \log \mathrm{kob} \mathrm{g}^{-1}$ olduğunu belirlemişlerdir. Benzer şekilde Morul ve İşleyici
(2012), Divle Tulum peynirlerinde TAMB sayısını 3.00 ile 9.02 $\log \mathrm{kob} \mathrm{g}^{-1}$ aralığında, ortalama olarak $6.78 \pm 1.42 \log _{\mathrm{kob} \mathrm{g}}{ }^{-1}$ olarak tespit etmişlerdir. Araştırmada elde edilen sonuçlar çalışmamızda elde edilen sonuçlar ile büyük ölçüde benzerlik göstermektedir.

Maya ve küfler, gıdalarda en sıklıkla görülen mikroorganizma gruplarıdır. $\mathrm{Bu}$ mikroorganizmalar gıda yüzeyinde kolaylıkla gelişerek ürünlerin bozulmasına ve tüketilemez hale gelmelerine neden olmaktadır (Ünlütürk ve Turantaş 2003).

Afyonkarahisar ilinde farklı ambalajlar içerisinde satışa sunulan Tulum peynir örneklerinde en düşük maya/küf sayısının $3.56 \log \mathrm{kob} \mathrm{g}^{-1}$ ile keçi sütünden üretilen ve tulum ambalaj içerisinde satışa sunulan örneklerde (Çizelge 6), en yüksek maya/küf sayısının ise; $6.92 \mathrm{log} \mathrm{kob} \mathrm{g}^{-1}$ ile koyun sütünden üretildikten sonra çuval ambalajlar içerisinde satışa sunulan örneklerde olduğu tespit edilmiştir (Çizelge 5).

Kara ve Akkaya (2015), Afyon Tulum peynirlerinde maya küf sayısının en az $<2.30 \log \mathrm{kob} \mathrm{g}^{-1}$, en çok $5.80 \log \mathrm{kob} \mathrm{g}^{-1}$ ve ortalama olarak $2.80 \mathrm{log}_{\mathrm{kob} \mathrm{g}}{ }^{-1}$; Demir ve ark. (2018) ise, Elâzı '̆' da ilinde satışa sunulan Şavak Tulumlarında en az 1.00 $\log \mathrm{kob} \mathrm{g}^{-1}$, en fazla $7.34 \log \mathrm{kob} \mathrm{g}^{-1}$, ortalama olarak 5.06 olduğunu belirlemişlerdir. Araştırmamız bulgularının çalışmalarda elde edilen sonuçlar ile kıyaslandığında Demir ve ark (2018), ile benzer, Kara ve Akkaya (2015)'ya ait sonuçlardan daha yüksek olduğu görülmüştür.

Laktik asit bakterileri, olgunlaşma sırasında tulum peynirlerinde tat ve aroma oluşumu üzerinde etkili olan bakterilerin başında gelmektedir. Bu bakterilerin sayısının fazla olmas1 ayrica koliform grubu gibi istenmeyen bakterilerinin gelişmesi üzerinde de baskılayıcı ve önleyici etki yapması açısından önemlidir (Kurt ve ark. 1991; Tekinşen ve Akar 2017).

Farklı ambalajlar içerisinde satışa sunulan tulum peyniri örneklerinin laktik asit bakterisi ve Lactococcus/Streptococcus spp. bakteri sayıları sırasıyla en düşük olarak $4.28 \pm 0.14$ ve $3.85 \pm 0.24 \log \mathrm{kob} \mathrm{g}^{-1}$ ile keçi sütünden üretilerek tulum ambalaj içerisinde satışa sunulan örneklerde, en yüksek olarak ise $4.72 \pm 0.11$ ve $4.65 \pm 0.88 \mathrm{log} \mathrm{kob} \mathrm{g}^{-1}$ ile inek sütünden üretilerek yine tulum ambalaj içerisinde satışa sunulan tulum peynirlerinde olduğu belirlenmiştir.

Farklı tulum peynirlerde laktik asit bakterisi sayılarınınbelirlendiği çalışmalarda incelendiğinde, Dinkçi ve ark. (2012), Karg1 Tulum peynirlerinde 7.06 log kob g-1 , Morul ve İşleyici (2012) ise, Divle Tulum peynirlerinde 6.67 $\log$ kob g $^{-1}$ laktik asit bakterisi olduğunu belirlemişlerdir. Kara ve Akkaya (2015), Afyon Tulum peynirlerinde Lactococcus/Streptococcus spp. sayılarını en düşük 5.14 $\log \mathrm{kob} \mathrm{g}^{-1}$, en yüksek $6.66 \log \mathrm{kob} \mathrm{g}^{-1}$ ve ortalama olarak ise $5.72 \log$ kob g $^{-1}$ olarak tespit etmişlerdir.

Koliform grubu bakterilerin gıda ürünlerinde yüksek sayılarda bulunması ürünlerin üretiminde uygulanan hijyen ve sanitasyon kurallarının yetersizliğinin ve/veya üretim sonrası oluşan kontaminasyonların göstergesidir. Staphylococcus aureus'un gıda sanayisinde en önemli bulaşma kaynağı ise gıda sanayisi çalışanlarıdır. $\mathrm{Bu}$ bakterinin gıdalardaki varlığı; uygulanan 1sıl işlemde sorun olduğunu, 1sıl işlem sonrası olası bulaşmaları ya da üretim ve ambalajlama aşamalarında insan kaynaklı kontaminasyonların varlığına işaret etmektedir (Ünlütürk ve Turantaş 2003). 
Çizelge 4. İnek sütünden üretilerek farklı ambalajlarda satışa sunulan Tulum peyniri örneklerinin mikrobiyolojik analiz sonuçları (log kob g-1). Table 4. Microbiological analysis results of Tulum cheese samples produced from cow's milk and sold in different packages (log cfu $\left.\mathrm{g}^{-1}\right)$.

\begin{tabular}{|c|c|c|c|c|}
\hline \multirow[b]{2}{*}{ Ambalaj } & \multirow[b]{2}{*}{ Analiz } & \multicolumn{3}{|c|}{ Numune (n: 15 x 3) } \\
\hline & & Minimum & Maksimum & Ortalama \\
\hline \multirow{6}{*}{ Tulum } & TAMB sayısı & 3.97 & 4.69 & $4.21 \pm 0.17$ \\
\hline & Maya/Küf sayısı & 3.69 & 4.62 & $4.45 \pm 0.22$ \\
\hline & TKGB say1sı & $<2$ & 3.31 & $1.18 \pm 0.26$ \\
\hline & LAB sayisı & 3.89 & 4.66 & $4.46 \pm 0.39$ \\
\hline & Lactococcus/Streptococcus spp. say1s1 & 3.59 & 4.79 & $4.65 \pm 0.88$ \\
\hline & Staphylococus aureus sayısı & $<2$ & 3.43 & $2.84 \pm 0.22$ \\
\hline \multirow{6}{*}{ Bidon } & TAMB say1s1 & 4.02 & 5.09 & $4.77 \pm 0.19$ \\
\hline & Maya/Küf sayısı & 4.18 & 4.72 & $4.48 \pm 0.69$ \\
\hline & TKGB sayıs1 & 2.01 & 3.67 & $2.65 \pm 0.94$ \\
\hline & LAB say1sı & 3.80 & 4.86 & $4.61 \pm 0.25$ \\
\hline & Lactococcus/Streptococcus spp. say1s1 & 3.85 & 4.28 & $4.04 \pm 0.22$ \\
\hline & Staphylococus aureus sayısı & 2.42 & 3.95 & $3.14 \pm 0.05$ \\
\hline \multirow{6}{*}{ Çuval } & TAMB say1s1 & 4.14 & 7.41 & $6.82 \pm 0.42$ \\
\hline & Maya/Küf sayısı & 4.61 & 5.36 & $4.76 \pm 0.28$ \\
\hline & TKGB sayıs1 & 2.95 & 4.04 & $3.53 \pm 0.27$ \\
\hline & LAB say1s1 & 4.57 & 5.12 & $4.72 \pm 0.11$ \\
\hline & Lactococcus/Streptococcus spp. say1s1 & 4.51 & 4.62 & $4.28 \pm 0.09$ \\
\hline & Staphylococus aureus say1s1 & 3.43 & 4.03 & $3.54 \pm 0.22$ \\
\hline
\end{tabular}

Çizelge 5. Koyun sütünden üretilerek farklı ambalajlarda satışa sunulan Tulum peyniri örneklerinin mikrobiyolojik analiz sonuçları (log kob $\mathrm{g}^{-1}$ ).

Table 5. Microbiological analysis results of Tulum cheese samples produced from sheep's milk and sold in different packages (log cfu $\left.\mathrm{g}^{-1}\right)$.

\begin{tabular}{|c|c|c|c|c|}
\hline \multirow[b]{2}{*}{ Ambalaj } & \multirow[b]{2}{*}{ Analiz } & \multicolumn{3}{|c|}{ Numune (n: 15 x 3) } \\
\hline & & Minimum & Maksimum & Ortalama \\
\hline \multirow{6}{*}{ Tulum } & TAMB sayıs1 & 3.42 & 4.02 & $3.51 \pm 0.26$ \\
\hline & Maya/Küf sayısı & 3.72 & 4.81 & $4.53 \pm 0.17$ \\
\hline & TKGB sayıs1 & 2.04 & 3.41 & $2.18 \pm 0.06$ \\
\hline & LAB sayisı & 3.38 & 4.71 & $4.52 \pm 0.48$ \\
\hline & Lactococcus/Streptococcus spp. say1s1 & 3.23 & 4.58 & $4.36 \pm 0.20$ \\
\hline & Staphylococus aureus say1s1 & 2.02 & 3.73 & $2.04 \pm 0.12$ \\
\hline \multirow{6}{*}{ Bidon } & TAMB say1s1 & 3.94 & 5.02 & $4.57 \pm 0.38$ \\
\hline & Maya/Küf sayısı & 4.68 & 5.09 & $4.76 \pm 0.41$ \\
\hline & TKGB sayısı & 2.12 & 3.52 & $2.56 \pm 0.14$ \\
\hline & LAB sayis 1 & 4.10 & 4.84 & $4.59 \pm 0.15$ \\
\hline & Lactococcus/Streptococcus spp. sayıs1 & 3.27 & 4.08 & $4.01 \pm 0.02$ \\
\hline & Staphylococus aureus say1s1 & 2.14 & 3.05 & $2.59 \pm .0 .05$ \\
\hline \multirow{6}{*}{ Çuval } & TAMB say1s1 & 4.16 & 7.21 & $6.92 \pm 0.31$ \\
\hline & Maya/Küf sayısı & 4.24 & 6.92 & $5.78 \pm 0.68$ \\
\hline & TKGB say1s1 & 2.06 & 4.67 & $3.23 \pm 0.13$ \\
\hline & LAB sayisı & 4.07 & 4.92 & $4.68 \pm 0.22$ \\
\hline & Lactococcus/Streptococcus spp. sayıs1 & 3.58 & 4.28 & $4.20 \pm 0.19$ \\
\hline & Staphylococus aureus sayis1 & 2.03 & 3.03 & $2.24 \pm 0.12$ \\
\hline
\end{tabular}

Çizelge 6. Keçi sütünden üretilerek farklı ambalajlarda satışa sunulan Tulum peyniri örneklerinin mikrobiyolojik analiz sonuçları (log kob g ${ }^{-1}$ ). Table 6. Microbiological analysis results of Tulum cheese samples produced from goat's milk and sold in different packages (log cfu $\left.\mathrm{g}^{-1}\right)$.

\begin{tabular}{|c|c|c|c|c|}
\hline \multirow[b]{2}{*}{ Ambalaj } & \multirow[b]{2}{*}{ Analiz } & \multicolumn{3}{|c|}{ Numune (n: 15 x 3) } \\
\hline & & Minimum & Maksimum & Ortalama \\
\hline \multirow{6}{*}{ Tulum } & TAMB sayıs1 & 3.73 & 4.81 & $4.16 \pm 0.28$ \\
\hline & Maya/Küf sayısı & 3.56 & 4.76 & $4.57 \pm 0.18$ \\
\hline & TKGB sayısı & $<2$ & 2.61 & $2.08 \pm 0.06$ \\
\hline & LAB sayisı & 3.66 & 4.61 & $4.28 \pm 0.14$ \\
\hline & Lactococcus/Streptococcus spp. say1s1 & 3.23 & 4.11 & $3.85 \pm 0.24$ \\
\hline & Staphylococus aureus say1s1 & 2.01 & 2.13 & $2.08 \pm 0.12$ \\
\hline \multirow{6}{*}{ Bidon } & TAMB say1s1 & 4.26 & 5.02 & $4.59 \pm 0.13$ \\
\hline & Maya/Küf sayısı & 4.26 & 4.75 & $4.56 \pm 0.28$ \\
\hline & TKGB sayıs1 & 2.12 & 3.65 & $2.74 \pm 0.12$ \\
\hline & LAB sayısı & 4.06 & 4.73 & $4.57 \pm 0.16$ \\
\hline & Lactococcus/Streptococcus spp. sayıs1 & 3.55 & 4.07 & $3.98 \pm 0.36$ \\
\hline & Staphylococus aureus sayıs & 2.26 & 3.14 & $2.63 \pm 0.11$ \\
\hline \multirow{6}{*}{ Çuval } & TAMB sayıs1 & 4.38 & 6.36 & $5.74 \pm 0.15$ \\
\hline & Maya/Küf sayısı & 4.33 & 5.86 & $5.62 \pm 0.12$ \\
\hline & TKGB sayıs1 & $<2$ & 2.04 & $2.01 \pm 0.07$ \\
\hline & LAB say1s1 & 4.18 & 4.92 & $4.64 \pm 0.13$ \\
\hline & Lactococcus/Streptococcus spp. say1s1 & 4.36 & 4.56 & $4.33 \pm 0.11$ \\
\hline & Staphylococus aureus say1sı & 2.03 & 2.41 & $2.09 \pm 0.01$ \\
\hline
\end{tabular}


Çizelge 7. Farklı sütlerden üretildikten sonra değişik ambalaj malzemeleri içerisinde satışa sunulan Tulum peynirlerinde Escherichia coli ve Salmonella spp. varlığı.

Table 7. After being produced from different milks, Tulum cheeses offered for sale in various packaging materials, Escherichia coli and Salmonella spp. presence.

\begin{tabular}{|c|c|c|c|c|c|c|c|c|c|c|c|c|c|c|c|c|c|c|}
\hline & \multicolumn{6}{|c|}{ İnek } & \multicolumn{6}{|c|}{ Koyun } & \multicolumn{6}{|c|}{ Keçi } \\
\hline & \multicolumn{2}{|c|}{$\begin{array}{c}\text { Tulum } \\
n=15\end{array}$} & \multicolumn{2}{|c|}{$\begin{array}{c}\text { Bidon } \\
\mathrm{n}=15\end{array}$} & \multicolumn{2}{|c|}{$\begin{array}{l}\text { Çuval } \\
n=15\end{array}$} & \multicolumn{2}{|c|}{$\underset{n=15}{\text { Tulum }}$} & \multicolumn{2}{|c|}{$\begin{array}{c}\text { Bidon } \\
\mathrm{n}=15\end{array}$} & \multicolumn{2}{|c|}{$\begin{array}{l}\text { Çuval } \\
n=15\end{array}$} & \multicolumn{2}{|c|}{$\underset{n=15}{\text { Tulum }}$} & \multicolumn{2}{|c|}{$\begin{array}{c}\text { Bidon } \\
n=15\end{array}$} & \multicolumn{2}{|c|}{$\begin{array}{l}\text { Çuval } \\
n=15\end{array}$} \\
\hline & $\mathbf{P}$ & $\%$ & $\mathbf{P}$ & $\%$ & $\mathbf{P}$ & $\%$ & $\mathbf{P}$ & $\%$ & $\mathbf{P}$ & $\%$ & $\mathbf{P}$ & $\%$ & $\mathbf{P}$ & $\%$ & $\mathbf{P}$ & $\%$ & $\mathbf{P}$ & $\%$ \\
\hline E.coli & 0 & 0 & 3 & 20 & 6 & 40 & 0 & 0 & 2 & 13.3 & 2 & 13.3 & 1 & 6.67 & 3 & 20 & 1 & 6.67 \\
\hline Salmonella spp. & 2 & 13.3 & 3 & 20 & 5 & 33.3 & 1 & 6.67 & 1 & 6.67 & 3 & 20 & 0 & 0 & 2 & 13.3 & 4 & 26.6 \\
\hline
\end{tabular}

P: Üreme Gözlenen Örnek Sayısı

Toplam 135 tulum peynir numunesinde en düşük toplam koliform ve Staphylococcus aureus türü bakteri sayıları; her iki bakteri içinde $<2 \log \mathrm{kob} \mathrm{g}^{-1}$ ile inek sütünden üretilip tulum ambalaj içerisinde satışa sunulan peynir örneklerinde, en yüksek toplam koliform ve Staphylococcus aureus türü bakteri sayıları ise sırasiyla $4.67 \mathrm{log} \mathrm{kob} \mathrm{g}^{-1}$ ile koyun sütünden üretilip çuval ambalajlar içerisinde satışa sunulan örneklerde ve 4.03 $\log \mathrm{kob} \mathrm{g}^{-1}$ ile inek sütünden üretildikten sonra çuval ambalajlar içerisinde satışa sunulan peynir örneklerinde olduğu belirlenmiştir (Çizelge 4).

Elazığ'da satışa sunulan Şavak peynirlerinde toplam koliform grubu bakteri sayısını Demir ve ark (2018), ortalama olarak $4.49 \pm 0.12 \log \mathrm{kob} \mathrm{g}^{-1}$, Demir ve ark (2017), ise üretildikten sonra vakum paketler içerisinde olgunlaștırılan tulum peynirlerinde ortalama $3.69 \log \mathrm{kob} \mathrm{g}^{-1}$ olarak tespit etmişlerdir. Morul ve İşleyici (2012), Kara ve Akkaya (2015) ve Demirci ve ark (2018), tulum peyniri örneklerinde Staphylococcus aureus türü bakteri sayılarını ortalama olarak sırasıyla 5.04, 2.91 ve $1.42 \log \mathrm{kob} \mathrm{g}^{-1}$ olarak saptamışlardır.

Üç farklı ambalaj malzemesi içerisinde satışa sunulan tulum peynir örneklerinde tespit edilen Escherichia coli ve Salmonella spp. cinsi bakteri varlığ 1 Çizelge 7'de gösterilmiştir. En fazla Escherichia coli ve Salmonella spp. türü bakteri varlığı sırasıyla 15 numunenin 6'sında (\%40) ve 5'inde (\%33.3) olmak üzere inek sütünden üretildikten sonra çuval ambalajlar içerisinde satışa sunulan örneklerde tespit edilmiştir.

Yapılan mikrobiyolojik analizler neticesinde elde edilen sonuçlar, konu ile ilgili diğer çalışmaların sonuçları ile genellikle benzer olmasına karşın bazı araştırmaların sonuçlarıyla uyumsuzlukların, tulum peyniri örneklerinin üretim, depolama, olgunlaştırma ve satış aşamalarında hijyen ve sanitasyon kurallarına yeteri kadar dikkat edilmemesinden, peynirlerin ambalajlanmasinda kullanılan malzemelerin mikrobiyal kalitesinin düşük olmasından ve ambalaj malzemelerin (özellikle çuval) içerisine konulan peyniri üretim sonrasında muhtemel kontaminasyonlardan gerektiği gibi koruyamamasından kaynaklandığg düşünülmektedir.

\section{Sonuç}

$\mathrm{Bu}$ çalışmada farklı sütler kullanılarak üretildikten sonra, farklı ambalaj malzemelerinde paketlenerek Afyonkarahisar ilinde satışa sunulan tulum peynirlerinin kimyasal ve mikrobiyolojik özellikleri belirlenmiştir.

Kimyasal analiz sonuçları açısından değerlendirildiğinde; bidon ambalajlar içerisinde satışa sunulan peynirlerinin, diğer ambalajlara kıyasla kurumadde ve yağ değerlerinin daha düşük, $\mathrm{a}_{\mathrm{w}}$ değerinin ise daha yüksek olduğu tespit edilmiştir. Bu durumun, bidon ambalajın özellikle su geçirgenliğinin, diğer malzemelere kıyasla çok daha düşük olmasından kaynaklandığı düşünülmektedir.
Tulum peyniri örneklerinde yapılan mikrobiyolojik analizler sonucunda elde edilen veriler incelendiğinde, en fazla mikroorganizma sayısının üç farklı süt çeşidi ile üretilen ve çuval ambalajlar içerisinde satışa sunulan örneklerde olduğu belirlenmiştir. Sonuçlar; tulum peyniri üretiminde, çuval ambalaj kullanımının, diğer ambalaj malzemeleri ile kıyaslandığında üretim sonrası olası kontaminasyonlardan ürünü yeterince koruyamadığını, bu ambalajlar içerisinde mikroorganizmaların daha kolay gelişebileceğini ortaya koymaktadır. $\mathrm{Bu}$ nedenle tulum peynirlerinin özellikle çuval ambalajlar içerinde olgunlaştırılması, depolanması ve satışa sunulmasının gerek peynirlerin mikrobiyolojik kalitesi ve gerekse tüketici sağlığı açısında uygun olmayacağı değerlendirilmiştir.

Türkiye'de en fazla tüketilen üç peynirden biri olan tulum peynirinin mikrobiyolojik kalitesi, yapımında genellikle çiğ süt kullanımı, proses aşamalarında bir standardın olmaması, üretim, ambalajlama, olgunlaştırma ve depolama aşamalarında yeterli hijyen ve sanitasyon kurallarına uyulmaması, uygun olmayan ambalaj malzemelerinin kullanımı gibi nedenlerden dolayı olumsuz etkilenmektedir.

Peynirlerin üretiminde kullanılan süte 1sıl işlem uygulanması, proses aşamalarının standardize edilmesi, üretim ve sonrasındaki aşamalarda olası kontaminasyonların engellenmesi, uygun ve güvenli ambalaj malzemesi kullanımı ile mevcut sorunların çözüleceği ve peynirlerin tüketici açısından daha güvenli hale geleceği düşünülmektedir.

\section{Kaynaklar}

Anonim (2001) Türk Standartları Enstitüsü, TS 6235 EN ISO 6887-1. Gıda ve Hayvan Yemleri Mikrobiyolojisi, Deney Numunelerinin Başlangıç Süspansiyonunun ve Ondalık Seyreltilerinin Hazırlanması İçin Genel Kurallar.

AOAC (2016a) Official methods of analysis (20th ed.). 942.15. Washington, DC: Association of Analytical Chemists.

AOAC (2016b) Official methods of analysis (20th ed.). 933.05. Washington, DC: Association of Analytical Chemists.

AOAC (2016c) Official methods of analysis (20th ed.). 930.15. Washington, DC: Association of Analytical Chemists.

AOAC (2016d) Official methods of analysis (20th ed.). 978.18. Washington: Association of Official Analytical Chemists.

AOAC (2016e) Official methods of analysis of the (20th ed.). 981.12. Washington: Association of Official Analytical Chemists.

Bostan K, Uğur M, Aksu H (1992) Deri ve plastik bidonlar içinde satışa sunulan tulum peynirlerinin duyusal, fiziksel, kimyasal ve mikrobiyolojik özellikleri. Pendik Hayv Hast Merk Araşt Enst Derg. 23: 75-83.

Ceylan ZG, Çağlar A, Çakmakçı S (2007) Some physicochemical, microbiological, and sensory properties of Tulum cheese produced 
from ewe's milk via a modified method. International Journal of Dairy Technology 60: 191-197.

Çakır Y, Çakmakçı S (2018) Some microbiological, physicochemical and ripening properties of Erzincan Tulum cheese produced with added black cumin (Nigella Sativa L.). Journal of Food Science and Technology 55(4): 1435-1443.

Çalım HG (2007) Konya ve çevresinde farklı tip ambalajlarda tüketime sunulan tulum peynirlerinin kalite nitelikleri. Doktora Tezi, Selçuk Üniversitesi Sağlık Bilimleri Enstitüsü, Konya.

Çetinkaya A (2008) Geleneksel Peynirlerimiz Abp Yayınları, İstanbul.

Demir P, Öksüztepe G, İncili GK, İlhak Oİ (2017) Vakum paketli Şavak tulum peynirlerinde potasyum sorbatın kullanımı. Kafkas Üniv Vet Fak Derg. 23(1): 23-30

Demir P, Erkan S, Öksüztepe G (2018) Elazı̆̆’da Satılan Şavak Tulum Peynirlerinin Mikrobiyolojik Kalitesi. Harran Üniv Vet Fak Derg. 7(1): 15-20.

Dinkçi N, Ünal G, Akalın AS, Varol S, Gönç S (2012) Kargı tulum peynirinin kimyasal ve mikrobiyolojik özellikleri. Ege Üniv. Zir. Fak. Derg. 49(3): 287-292.

Flowers RS, D'aust JY, Andrews WH, Bailey JS (1992) Salmonella (Ed: Vanderzant DF), Compendium of the Methods for the Microbiological Examinations of Foods.. Spilttstoesser. American Public Health Assocition, s. 371-42.

Greenwood MH, Coetzee EF, Ford BM, Gill P, Hooper WL, Matthews SCV, Patric S (1984) The microiology of selected retail food products with an evolation of vialable counting methods. Journal of Hygiene 92: 67-77.

Halkman K (2005) Gıda mikrobiyolojisi uygulamaları. Başak Matbaacılık Ltd. Şti, Ankara,

Halkman K, Sağdaz ÖE (2011) Gıda mikrobiyolojisi uygulamaları. Prosigma Baskı ve Promosyon Hizmetleri, Ankara.

ISO (1991) International Standard Organization. 4832 General Guidance fort the Enumeration of Coliforms Colony Count Technique. Geneva, Switzerland.

ISO (1999) International Standard Organization. 6888-1 Horizontal Method for the Enumeration of Coagulase- positive Staphylococci Technique using Baird Parker Agar Medium. Geneva, Switzerland.

ISO (2001) International Standard Organization. 16649-1:2001 Microbiology of food and animal feeding stuffs, Horizontal method for the enumeration of beta-glucuronidase-positive Escherichia coli Part 1: Colony-count technique at 44 degrees $\mathrm{C}$ using membranes and 5-bromo-4-chloro-3-indolyl beta-D-glucuronide. Geneva, Switzerland.

ISO (2008) International Standard Organization. 21527-1:2008 Microbiology of food and animal feeding stuffs, Horizontal method for the enumeration of yeasts and moulds Part 1: Colony count technique in products with water activity greater than 0,95 . Geneva, Switzerland.

ISO (2013a) International Standard Organization. 4833-2:2013 Horizontal method for the enumeration of microorganisms. Part 2:
Colony count at 30 degrees $\mathrm{C}$ by the surface plating technique. Geneva, Switzerland.

ISO (2013b) International Standard Organization. 4833-1:2013 Microbiology of the food chain. Horizontal method for the enumeration of microorganisms. Part 1: Colony count at 30 degrees $\mathrm{C}$ by the pour plate technique. Geneva, Switzerland.

ISO (2015) International Standard Organization. 166493:2015Microbiology of the food chain. Horizontal method for the enumeration of beta-glucuronidase-positive Escherichia coli Part 3: Detection and most probable number technique using 5-bromo-4chloro-3-indolyl-ß-D-glucuronide. Geneva, Switzerland.

ISO (2017) International Standard Organization. 6579-1:2017 Horizontal method for the detection, enumeration and serotyping of Salmonella. Geneva, Switzerland.

Kara R, Akkaya L (2015) Afyon Tulum Peynirinin Mikrobiyolojik ve Fiziko-Kimyasal Özellikleri ile Laktik Asit Bakteri Dağılımlarının Belirlenmesi. AKÜ Fen ve Müh. Bil. Derg. 15: 1-6.

Karaca OB, Ocak S, Güney O, Güven M (2007) Present situation of goat production sector and some typical dairy cheeses. In: Turkey, 3rd Joint Meeting of the Network of Universities and Research Institutions of Animal Science of The South Eastern European Countries. Hessaloniki, Greece, pp. 120-125.

Kirdar SS, Kose Ş, Gun I, Ocak E, Kursun Ö (2015) Do consumption of Kargi Tulum cheese meet daily requirements for minerals and trace elements? Mljekarstvo 65(3): 203-209.

Kneifel W, Berger E (1994) Microbiolgical criteria of random samples of spices and herbs retailed on the austrian market. J Food Protection 57(10): 893-901.

Kurt A, Çağlar A, Çakmakçı S (1991) Erzincan (Şavak) Tulum peynirinin mikrobiyolojik özellikleri üzerinde bir araştırma. Doğa Tr J. of Vet and Anim. Sci. 16: 41-50.

Morul F, İşleyici Ö (2012) Divle Tulum peynirinin kimyasal ve mikrobiyolojik özellikleri. YYU Veteriner Fakultesi Dergisi 23(2): 71-76.

Sekin Y, Karagözlü N (2004) Gıda Mikrobiyolojisi, Gıda Sanayisi İçin temel Prensipler ve Uygulamalar. Literatür Yayınevi, İstanbul.

Tekinşen C, Tekinşen K (2005) Süt Ürünleri Teknolojisi. Selçuk Üniversitesi Veteriner Fakültesi Yayınevi, Konya.

Tekinșen KK, Akar D (2017) Erzincan Tulum peyniri. Ata Üniv Vet Bil Derg. 12(2): 218-226.

Tomar O, Akarca G, Beykaya M, Çağlar A (2018) Some characteristics of Erzincan Tulum cheese produced using different probiotic cultures and packaging material. Kafkas Uni. Vet. J. 24(5): $647-$ 654.

Ünlütürk A, Turantaş F (2003) Gıda Mikrobiyolojisi. Üçüncü Baskı. Meta Basım ve Matbaacılık, İzmir. 